\title{
Leadership and Empowerment
}

\section{INTRODUCTION}

Every nurse is a leader. The process of completing healthcare training, establishing oneself as a human caretaker, and joining a global network of healers establishes a nurse as a leader. The degree to which each nurse leads will vary, but every nurse leads in one way or another. Despite the nurses' natural propensity toward leadership, the COVID-19 pandemic of 2020 illustrated the lack of nursing leadership at every level perfectly.

In this chapter we discuss nursing leadership at the national, institutional, and individual levels; identify the lack of nursing leadership in healthcare; and discuss pathways to increase nurse leadership throughout healthcare. There are books, theories, articles, and oodles of people who give instruction on "leadership" and how to be a "good leader" or even an "excellent leader." Among all 
of these guides are a plethora of works outlining "nursing leadership" and describing how to be a nurse leader. Yet, as a profession, we find ourselves without substantial leadership within the healthcare system. The elephant in the room is that healthcare is dominated by nurses, yet nurses do not lead healthcare. This conundrum has perplexed me for years.

There are several factors contributing to the lack of nursing leadership in healthcare. These include but are not limited to a history of subordination, professional infighting, and professional shortsightedness. Some of these pitfalls are woven tightly into the culture of professional nursing.

\section{National Leadership}

There is no unifying national nursing organization in the United States. This is largely due to the fractured and dysfunctional organizational culture within the nursing profession. Nursing organizations, as a rule, do not work in unison, nor do they agree on their methods of empowering individual nurses and/or the nursing profession. Moreover, most nurses are not members of the largest, self-proclaimed, national nursing organizations.

As national (or international) healthcare-related problems arise, the public does not turn to "national nursing organizations" as a healthcare authority. Moreover, and generally, national nursing organizations are not viewed as authorities on healthcare and due to the fractured member base and messaging do not lead the nursing profession or healthcare at large. To put this in immediate context, during the COVID-19 global pandemic, frontline healthcare providers were understaffed, were under-resourced, and bore the brunt of the virus as healthcare systems became overwhelmed. The problems with understaffing and nurses not having enough protective equipment trended on international news, national news, and social media networks 
for months. All of the nursing organizations made statements about the issues nurses were facing, and many made efforts to help frontline healthcare workers. Yet none of the major nursing organizations in the United States made the national or international news circuit in any substantial way. The individual efforts of nursing organizations went largely unnoticed. In this instance, professional shortsightedness was on full display. The COVID-19 global pandemic was an opportunity for nursing organizations to unite behind one common cause and elevate the nursing profession as the science-based global leader in healthcare. This did not happen. Truthfully, the world has yet to turn to the nurse for solutions to big healthcare problems.

\section{Institutional Leadership}

In Chapter 4, we discussed who controls healthcare and how institutional nursing leaders are often powerless by comparison. The reimbursement system in healthcare ensures that all nursing leaders, from the chief nursing officer to the night shift charge nurse, are empowered just enough to minimize losses associated with employing nurses but not empowered enough to disrupt the system at large. The healthcare system places some nurses in positions of "authority" in such a way that it gives the illusion of authority, yet these nurses are not actually empowered enough to lead their institutions. At best, nurse leaders within institutions can mitigate revenue losses and be buffers between corporate leadership and nursing staff. Again, throughout the COVID19 pandemic, institutional nursing leadership proved to be relatively powerless when it came to protecting their staff.

\section{Individual Leadership}

Nurses truly shine at the individual leadership level. Individual nurses are trusted by the public and by 
their peers. However, there is a history of subordination imposed by the practice of medicine onto the practice of nursing. Historically, most physicians were men. The practice of nursing was dictated by and delegated from male physicians to female nurses. These demographics are now shifting, with more women becoming physicians and more men becoming nurses. However, the system that positions one group as reliant on and deferential to the other still exists. A classic example of this dynamic is that nurses still rely on "orders" from medical providers to conduct some of their work. This is a long-standing and necessary part of the healthcare system. However, the overtones and subsequent culture this creates undermine nurses leading in healthcare.

Still, the history of nurses being subordinate is an old narrative. In this narrative, women in little white hats stand when a physician enters the room, slink into the background, and retrieve a cup of coffee prepared "just the way he likes it." These days are long gone, but the paradigm still exists to some degree.

Hope is not lost. More and more, we see nurses practicing at the highest level of their licensure, asserting their insights and skills, and working alongside physicians as colleagues and team members. To shift this narrative even further, nurses must remove this concept of subordination from the profession entirely and assume a position of professional parity with physician colleagues. This is not to say that nurses and physicians have the same knowledge base or training but rather the professions are equally reliant on each other to provide care. This bold kind of vision would recognize that both physician and nurse roles are equally important. The modern healthcare system does not allow space for a physician to physically provide care for wards full of 
patients. The physician is reliant on the nurse to do this work. Similarly, the system is designed in such a way that even very qualified nurses rely on expert medical opinions and direction from physicians. Nurses are not trained physicians and rely on physicians for complex medical decision-making.

\section{CHANGING THE NARRATIVE}

The lack of nursing leadership within healthcare is an old narrative. The void of nursing leadership at the national and international levels is a direct result of professional shortsightedness. Leaders of professional nursing organizations are so bogged down in dogmatic approaches and territorial squabbles that they rarely make it to the national or international stage. Nurses at the institutional leadership level are mostly concerned with being a buffer between senior leadership and staff. At the individual level, nurses are mostly concerned with patients and communities.

This professional shortsightedness is a symptom of the history of subordination and professional infighting. Nursing professional culture is such that nurses are satisfied with simply being noticed enough to be invited to the leadership table. This mentality is part of the problem. As the largest force within healthcare, nurses should have significant representation at leadership tables at every level.

Every nurse is a leader in some way. However, for nurses to lead and revolutionize healthcare, every nurse must extend their leadership beyond the bedside. There are three essential principles that will help every nurse lean into their leadership potential: knowing one's preferred leadership style, recognizing and filling systemic voids, and positive disruption to the status quo. 
The first and most important factor in leadership is to know and understand what type of leader you are. There are many leadership styles. The information in Box 5.1 is not an exhaustive list of definitions of these leadership styles but rather is meant to highlight the positive attributes of each leadership style. These leadership styles may be useful in healthcare settings.

The most important first step is to recognize and embrace your preferred leadership style. Some would argue that certain leadership styles are better than others. This is misleading. Each leadership style can be useful. To be effective, the style should be comfortable for the leader and appropriate for the situation. For example, in a small group medical practice, where all of the team members are equally competent and ranked, a democratic leadership style may be helpful. Contrarily, in military medicine, an autocratic style may be more useful. Every nurse should spend some time understanding what leadership style suits them.

\section{B0X 5.1 Leadership Type Definitions}

Visionary: Inspirational, drive progress, earn trust easily

Servant: Work alongside the team, focus on colleague satisfaction, morale builders

Autocratic: Authoritarian, efficiency and compliance focused

Democratic: Consideration of team input fosters high employee engagement

Transformational: Focus on communication, goals, commitment to organization

Transactional: Focus on mentorship, achieving goals, enjoying rewards 
Throughout my career I've been gently pushed into leadership positions. This was likely due to several factors, including being a man, my personality, my work ethic, and having some level of ambition. However, I was never interested in leadership in any way. In fact, I balked at the idea of being "in charge of anyone" aside from myself. This attitude persisted even as I was being nudged into leadership roles while I completed several nursing programs, worked several different kinds of healthcarerelated jobs, and was well into my doctoral training.

During my last graduate degree training, the dean of the school mandated leadership training as part of doctoral education, specifically for academic degrees. He gave the rationale that too many people were graduating with PhDs who didn't understand leadership. Nonetheless, it was during this training that I learned that I prefer the servant leadership style. This likely stems from my own discomfort with authority and not wanting to be a "bossy boss." This was a powerful revelation and allowed me to step into leadership roles with more comfort as I knew how I preferred to lead. The revelation was that people sought me out as a leader because I liked to lead from within the pack. This was comfortable for the people who worked with me but also comfortable for me as I didn't even recognize I was enjoying leadership.

The second principle that helps nurses lean into leadership is recognizing and filling systemic voids. Every employed nurse can point out the dysfunction, problems, and issues within the healthcare system or institution in which they work. Recognizing the problems, or the voids, in the system is rarely a problem for nurses. Nurses struggle with taking action to fill the voids they see.

The third factor in leadership is positive disruption of the status quo. Taking bold action can be difficult and downright terrifying, especially if we consider our livelihood is tied to what we do or do not do professionally. 
However, in order to really step into leadership, nurses must stop asking for permission to do the right thing. We must be brave enough to do the right thing and challenge those in power to contest us publicly for doing what is right. We should never push ethical or moral boundaries. However, professional boundaries are fair game if our actions are truly making things better.

I worked for a large agency that had high turnover at the medical director level, so much so that there were three new medical directors within 3 years, as well as rapid turnover at the medical provider level. Staff morale was low, and the patients were frustrated with poor care continuity. Word "on the street" was that medical care at this agency was not very good.

The regulatory bodies for this specialty required a physician to serve as medical director and oversee the medical practice at this agency. The agency charged the medical director with overseeing the department in which I worked as well as provided care to patients. This model excluded me, a nurse, from leadership within the agency. However, my time working at the agency allowed me to see the problem differently than senior leadership.

As an APRN I wasn't sure exactly what the medical director job entailed, but I knew there was likely a systemic problem. I knew the agency was far too large and the practice far too unwieldy for one person to manage. I made a proposal to the senior leadership that I take on some of the responsibilities of the medical director role on a trial basis. My compromise was that I would work my regular clinical job in addition to helping at the leadership level.

As a servant leader, this was most suitable for me. I loved to work alongside the providers and solve problems. My goal was to make the agency a destination for nurses and providers. I believed that if we took better care of the staff, they would in turn take better care of the patients. 
I worked tirelessly in this unofficial role for 1.5 years, during which time I studied the problems and worked with other staff to fix them. After 12 months of work, the medical department stabilized. After 18 months, the medical department was completely transformed. We hired excellent staff, compensated them well, and included them in process improvement. We had a wait list of people applying for nursing and APRN jobs. We were more productive than we'd ever been in the history of the agency. The staff was very happy and the complaints from staff and patients slowed to a trickle. I then proposed to leadership that my position be made official and was promoted to director, working alongside the physician medical director (who had different responsibilities). This is an example of recognizing the void in the system (high turnover, low employee satisfaction, unsustainable workload) and being a positive disruptor (nurse creating leadership roles in a space typically filled by physicians).

The ladder of engagement can help illustrate how every nurse can lean into leadership, broaden their influence, and capitalize on the fraternity of the nursing profession. This ladder of engagement approach still requires the nurse to understand what type of leader they are, recognize voids in systems, and fill the voids by being a positive disruptor. See also Table 1.1 and Table 5.1.

Level 1: Unaware-Unaware of the issues or have accepted the status (students, novices)

Level 2: Aware, unengaged-Aware of the issues; do not participate in addressing them

Level 3: Minimally engaged-Unlikely to engage online; may participate in online activities if convenient

Level 4: Moderately engaged-Passively engaged online; may participate in an in-person event if convenient 
Level 5: Highly engaged-Seek out opportunities to engage online, likely to engage in person, will participate if the pathway is created, seek out and address issues

Level 6: Activist-Change agents directly engaged in advocacy, policy making, and creating dialogue. These are highly visible entrepreneurs, innovators, and leaders who create engagement opportunities for self and others and seek out and engage issues. For example, students and practicing nurses at levels 1 and 2 may be unaware of their ability to lead.

\section{Table 5.1 Leadership and Level of Engagement}

\begin{tabular}{llcc} 
Level & Individual & Institutional & $\begin{array}{c}\text { National and } \\
\text { International }\end{array}$ \\
\hline 1,2 & $\begin{array}{l}\text { Understand } \\
\text { leadership } \\
\text { type }\end{array}$ & $\mathrm{x}$ & $\mathrm{x}$ \\
\hline 3,4 & $\begin{array}{l}\text { Understand } \\
\text { leadership } \\
\text { type }\end{array}$ & Assert change & $\mathrm{x}$ \\
\hline 5,6 & $\begin{array}{l}\text { Understand } \\
\text { leadership } \\
\text { type }\end{array}$ & Assert change & $\begin{array}{l}\text { Create mass } \\
\text { direction }\end{array}$ \\
\hline
\end{tabular}

Every nursing school curriculum should include leadership training (not to be confused with management training). The goal of this training should be to introduce pathways to leadership at the individual, institutional, regional, and national levels. Nurses who are not in formal leadership positions should familiarize themselves with leadership styles, specifically the leadership styles of those within their institution, as well as any gaps within the structure. Once comfortable at levels 1 and 2, nurses should move to levels 3 and 4 . 
Nurses at levels 3 and 4 may be in lower (i.e., charge nurse) to executive level leadership (i.e., chief nursing officer). These nurses should consider and evaluate their leadership style and familiarize themselves with the leadership structure within their institution as well as any gaps within the structure. These nurses are positioned to assert themselves as change agents within their health system. As change agents, these nurses seek to create positive and sustainable culture shifts that empower subordinates and peers. These nurses should push the boundaries of their leadership roles by being positive disruptors. I have witnessed a great deal of unjustified angst when nurses reach the leadership table. This may be an acceptable barrier for the novice leader; however, in order for nurses to truly lead, we must be prepared to take bold and decisive action. When posed with the option to "do the right thing" it is better to ask for forgiveness than permission.

Nurses at levels 5 and 6 are at the national and international leadership levels and may be well established nurse scientists, leaders of professional organizations, and established change agents.

These nurses often understand leadership well and know what type of leader they are as well as how to assert change within institutions and systems. These nurses are influential within their sphere and in prime position to direct a nation on healthcare-related strategies. However, the general population does not seek information from these nurses. These nurses are rarely front and center during a national, international, or systemic health crisis, even though these nurses are in an optimal position to lead and direct healthcare and planning on a mass scale. These nurses are also in prime position to amplify their impact by forming coalitions with other nursing organizations, disrupting the status quo, and revolutionizing healthcare. 


\section{NURSING POWER}

Similar to the literature on leadership, there is a plethora of information available about empowerment, specifically nurse empowerment. Despite all of this information being readily available, nurses consistently report feeling powerless (Adkins, n.d.). Traditional nursing professional culture does not promote individual or collective empowerment. Nurses are trained to advocate for patients. In general, nurses are not encouraged, trained, or empowered to advocate for themselves, their colleagues, the nursing profession, or the general public. If, by chance, a nurse is empowered enough to advocate beyond the bedside, rest assured they have arrived at this juncture through sheer determination.

\section{Disempowerment Factors}

Nurses consistently describe feeling as if they are unable to make significant changes in their professional lives. There are several reasons why nurses feel disempowered. Factors include but are not limited to a professional culture that does not promote empowerment, competing personal and professional interests, a constant need to mitigate risks, and culturally ingrained cynicism.

Professional Culture: Many aspects of professional nursing culture are the antithesis to empowerment. On a systemic level, the concerns of nurses are largely ignored. Nurses are constantly understaffed, underpaid, overworked, disrespected, and mistreated. Aside from collective bargaining agencies, there are only a few weak internal mechanisms that can check the power of the healthcare system in any meaningful way. From a cultural perspective, it is common practice to offer pizza or other small tokens of appreciation to worn out and demoralized 
nursing staff. It is common for disempowered nursing staff to reach the breaking point. Soon after, the rumors that the staff has contracted a case of "the quits" start to circulate. There are few things that more clearly convey the message that people don't have any power than management's providing a slice of terrible cold pizza to quell the rumblings of disgruntled staff. As silly as this sounds, it is a common practice that plays out over and over again in healthcare facilities throughout the United States. Finally, on an individual level, nursing culture is inundated with undermining and self-defeating practices that constantly inhibit progress (e.g., lateral violence and bullying). It is difficult to feel empowered in an environment where colleagues battle about everything, nothing at all, and all in between.

Competing Interests: A major barrier to nurses becoming empowered are competing interests of family life. Nurses, most of whom are women, are constantly fighting battles on two fronts: home life and work life. Nurses may know what the problems are in healthcare and likely have thought of solutions to the problems. However, when the decision to devote energy to taking professional action is juxtaposed against devoting energy to a family, naturally most people will choose family first.

Mitigating Risk: In addition to navigating competing interests, nurses must mitigate risk associated with taking any stance beyond the status quo. Nurses, particularly those who work in right-to-work states or do not have union protections, often find themselves in the precarious situation of deciding if speaking up is worth losing their job. This is why despite there being "regulations" outlining rules for nurse work environments, those rules are seldom followed, and almost no one ever reports when rules are broken. Many nurses are stuck between staying in a 
bad job and getting fired for trying to improve it. Lastly, job loss is on the extreme end of risk mitigation. Loss of career momentum is also a risk that many nurses are not willing to take.

Cynicism: Cynical attitudes are pervasive in nursing culture. This is not limited to any demographic or age group. I can't count how many times I've heard a seasoned nurse say, "It's been this way forever," followed by, "Nothing will change." The millennial generation tends to view careers differently than other generations; they are the least likely generation to stay with a single employer long term and the most likely generation to change jobs frequently (American Sentinel University, 2017). This is not necessarily a negative culture shift but rather a reflection of how a generation of people has shifted from focusing on work to focusing on self-interests. The result is a hopeless senior generation and younger generation that isn't interested in wasting energy on fruitless efforts.

\section{Pathways to Empowerment}

As nurses, we must know and understand the rules of engagement before we can empower or be empowered. Empowerment in nursing starts with our own individual practices. This is where nurses are most comfortable. In order to truly revolutionize healthcare, nurses must extend this power beyond the bedside to our colleagues, our institutions, our local communities, and throughout the world.

Practice: Every nurse has the opportunity to be a leader in their individual practice. However, before we can be an exemplar of good nursing practice, we must know "the rules" of our practice-in other words, know the job and the role within the team as well as the expectations 
of colleagues and patients. Most important, every nurse should know and understand the scope of practice as decreed by their local board of nursing. I cannot emphasize this last point enough.

Many nurses have been reported to their board of nursing after an unintentional infraction. For example, I once worked at a practice where I was fairly well known and liked (presumably). In this practice I was formally recognized as a leader, an exemplar of professionalism and good clinical practice. A colleague at this same practice confided in me that they wanted to seek medical care for a condition but could not afford a visit with their primary care provider. The colleague asked me to treat them. I collected the necessary medical history and gave them a prescription. I had observed my physician and APRN colleagues treating other colleagues as a common practice. However, I had unknowingly broken the law. I had performed care without documenting the encounter, which is illegal in my state. I was thus reported to the board of nursing. The investigation led to remediation (learning laws and statutes pertinent to my practice), a probationary period, and a permanent mark on my license. The moral of this story is that I was an exemplary employee who was attempting to help a colleague. My intentions were good. However, my ignorance of the legal practice authority had real consequences. My own ignorance tarnished my role as a stellar employee, advocate, and clinician.

Through this experience I learned that, as nurses, we cannot win the game if we don't know the rules. Fortunately, I also learned more about the scope of my practice. Importantly, I learned that the board of nursing makes the rules for nursing practice in each state, and it is up to each individual nurse to be familiar with these rules. In this situation, it wasn't enough for me to be satisfied with being a good clinician or being helpful to my colleagues. Had I known and fully understood the rules 
of engagement, I would have had a greater chance of having a positive impact. In order to truly be powerful in a space, we must know the rules of the space we occupy.

Colleagues: Healthcare is hierarchical by design. There are administrators who manage staff and facilities; interns, residents, and attending physicians who give orders; charge nurses and unit managers; and a constant stream of novices and student learners. It takes years for the novice to truly understand all of the roles in a healthcare team and sometimes longer to understand who truly holds power. It is a curious thing to figure out who, of all the people milling around a healthcare facility, has power and who has influence. Power and influence are not synonymous in these settings. An administrator may seem powerful if they are listed as a "Director of XYZ Department"; however, it may be the nurse with 25 years of experience who has the greatest influence over the environment and the team.

I once worked as a staff nurse with a charge nurse we called "Scary Mary." She was terrifying. Scary Mary presented as a traditional middle-aged veteran nurse and she ran a very tight ship. I was a young male nurse with a patchy beard and dreadlocks that hung midway down my back. To say we came from different worlds would be an understatement. Every day that I worked on Scary Mary's unit I thought to myself, "I don't think I can work with this lady."

I watched the staff scurry and jump to attention when she gave orders. I noticed that the physicians gave her their full attention when she spoke. The patients seemed to know that her word was the last word. Nevertheless, I fell in line like everyone else on her unit. Over time, I got to know Scary Mary, and I learned that she was not scary at all. Her work was impeccable. She was respected and her influence was powerful. To some people, she 
was intimidating. Staff who couldn't "hack it" on Scary Mary's floor were magically assigned to different units. Everyone else fell in line. I enjoyed the work but was at my wit's end with Scary Mary's military precision.

One day I asked Scary Mary to give me an explanation for an order she gave me. She answered factually, and it wasn't scary at all. I decided to ask her to teach me more of what she knew, and to my surprise she did so happily. She taught me her rules, methods, and tricks. Eventually, I stopped asking but she kept giving me her little pearls. When it was time for a charge nurse to be trained for a different unit, my name came up. I excitedly told Scary Mary about my promotion, to which she replied, "Yes, I know. Who do you think told them to put you there?"

When I started working at Scary Mary's hospital, I completed new employee orientation. I learned who all of the bosses were. I learned about all of the "important" people in the hospital, but no one told me about Scary Mary. It would take me 2 years to understand all of the players in the hospital, such as who had power and who had influence. I learned that the people who have power and influence in healthcare settings are not always who we expect. The moral of this story is not to get chummy with people who can help your career (though that doesn't hurt). Instead, the moral of the story is that it is important for nurses to empower each other. It is equally important for every nurse to know and understand the visible and invisible leadership structures in which they work, who holds power, who holds influence, and who holds both.

Institutions: In many ways, healthcare professionals work and operate on a need-to-know basis within their healthcare institutions. Regardless of the size of the healthcare facility or institution, we are expected to show up, do our work, and avoid meddling in anything that isn't our 
responsibility. We've all heard a colleague say, "That's not my job." Whether we cringed when we heard the words or agreed with the sentiment, we understood that our colleague believed in staying in their lane.

Healthcare is moving toward more integrative and interdisciplinary care team models. Yet our view of the healthcare institution is often limited to our most proximal colleagues, staff, and workflows. This way of being in the workplace is problematic for many reasons. First, our view is limited. Think of the viewpoint of the eagle and a beaver living in the same habitat. When an eagle soars high above a field, they can see miles into the distance in multiple directions. They can see storms approaching as well as other animals moving on land and in the air. They can see the movements of small animals on the ground. They can see features of the landscape like hills, valleys, waterways, and fields. The eagle knows all of the borders of the terrain and can oversee the entire ecosystem.

The beaver, in contrast, can see the stream of water, the dam they built, and the pond they cultivated. They can see their home made of logs and all of the other animals that inhabit their small pond. Indeed, the beaver knows nearly everything about the pond.

The beaver view, being close to the ground and deep within the habitat, helps the beaver find and secure its needs. Similarly, the eagle view, being high above the habitat, helps it find and secure its needs. However, the eagle knows little about the beaver pond, and the beaver has never seen the mountains in the distance. The viewpoints of the eagle and the beaver are useful, but neither fully understands or can even conceptualize the other's viewpoint.

Nurses, like other healthcare professionals, often work like beavers. In this scenario, their view of the institution (or the ecosystem) is often limited to their daily workflows at worst or workflows within the institution at best. When a beaver makes a dam, they are not concerned with 
subsequently flooding an adjacent field or displacing other animals. They are just doing their work. As nurses, we are often "too busy" to be concerned with the larger ecosystem and don't actually see beyond our daily work.

Meanwhile, the eagle knows that the beaver built the dam, which created the pond that supplies fish for its consumption. However, the eagle cannot see the granular details of the beaver dam. The eagle is unaware of how much effort the beaver used to build its home or what the beaver does on a day-to-day basis. Healthcare institutional leaders are like eagles. They can see far and wide but can rarely connect with or appreciate what's happening on the ground. This disconnect between leadership and frontline employees happens in many industries and is not unique to nursing. The point of this analogy is that the nurses within a healthcare institution cannot be empowered unless the people with the eagle view and the people with the beaver view are the same people. To empower the profession of nursing, more bedside nurses need to assume leadership roles, and they must never forget the view from the bedside.

National and International: There are countless nongovernmental organizations working to relieve illness and improve health around the United States and around the world. Considering how many nurses make up the healthcare workforce, very few healthcare organizations are nurse led or offer the nursing approach to solve complex health problems. There are few nurses leading national or global health efforts. The United Nations has almost no nurse-led global initiatives. There are no nurse positions a person can be appointed to at the federal level in the United States. Occasionally, a nurse is elected to Congress. However, Congress does not have a committee dedicated to health. There are no nurses on the U.S. Senate's health education, labor, and pensions 
committees. Despite the contributions of nurses to the health and well-being of nearly all of the humans on the planet, it is quite uncommon to see nurses empowered, visible in the public eye, and at the leadership table with heads of state.

The World Health Organization (WHO) declared 2020 the year of the nurse. Yet there are few nurse-led initiatives anywhere in the world. The national and international power of nurses is as invisible as the leadership positions we've never been allowed to have. If we want to empower nurses through our institutions, communities, nations, and the world, we must ensure they see themselves reflected as leaders at every level of leadership.

\section{CONCLUSION}

The levels of engagement model is a good way to conceptualize how every nurse is a leader and has potential for leadership beyond the bedside. The levels in this instance include examining and learning preferred leadership style, asserting change at the institutional level, and asserting change at the national and international levels. Regardless of where a nurse is on the ladder of engagement, they can move to the next level and should encourage other nurses to do so as well.

There are several factors that disempower nurses, including negative aspects of nursing culture, competing interests, need to mitigate risk, and cynicism. Every nurse should engage and dismantle negative nursing culture, promote a culture that diminishes bullying, reject cynicism, and generally build a more supportive collegial culture within the nursing profession.

Regardless of how busy their home life is, every nurse can engage in small meaningful ways that help elevate the nursing profession. A nurse who is being kind and supportive to their colleague and the nurse who is elected 
to Congress are both empowering and revolutionizing the profession. Every positive action beyond the bedside is important.

Similarly, it is essential that nurses know the limits of their professional boundaries. We cannot be empowered or empower others if we do not know the rules and laws that govern our practice. Every nurse must know where they've been, where they are, and where they're going professionally. Empowerment cannot happen without direction.

In order to truly be powerful in a space, we must know the rules of the space we occupy. A direct path to empowering nurses in practice includes being well versed in and fully understanding the laws that govern practice as dictated by the board of nursing. Every nurse should not only know the laws that govern their practice but should be able to help others understand these rules as well.

It is important for nurses to empower each other as well as to be well acquainted with the visible and invisible leadership structures in their institutions. To have influence we must understand who holds power, who holds influence, and who holds both.

Nurses who have moved from the bedside to leadership have an excellent vantage point from which to empower other nurses. More bedside nurses need to assume executive-level leadership roles from which they can lift the system, their colleagues, and the profession at large. Lastly, if we truly want to empower nurses we must ensure that nursing leaders are highly visible at the institutional, community, state, federal, and global leadership levels.

\section{DISCUSSION AND REFLECTION POINTS}

1. What is your level of engagement as a leader?

2. What is your preferred leadership style? 
3. Are there any disempowering or competing interests that prevent you from being a more influential leader?

4. What is your typical reaction to cynicism in the workplace?

5. Review your local board of nursing website.

a. Did you find anything surprising?

6. Who are the official leaders in your institution?

a. Who are the unofficial leaders in your institution?

7. Name a nurse in leadership.

a. Institution level

b. Regional level

c. State level

d. Federal level

e. National level

f. Global level

\section{REFERENCES}

Adkins, A. (n.d.). Millennials: The job-hopping generation. https://www.gallup.com/workplace/231587/millennialsjob-hopping-generation.aspx

American Sentinel University. (2017). Secrets of effective nurse leaders: EMPOWERMENT. The Sentinel Watch. https://www.americansentinel.edu/blog/2017/05/09/ secrets-of-effective-nurse-leaders-empowerment/ 